\title{
Los cuerpos de la revuelta
}

\section{( Laura A. Arnés* (IIEGE/UBA/CONICET)}

El texto de Brad Epps me interpela desde la incertidumbre, me lanza hacia derivas que, como toda deriva, empiezan pero no terminan. Pero además, me trae a la memoria un texto de Adrienne Rich que, en mi recuerdo, ya no es más que una frase: "No lo superamos si no se fue. No somos leales si no está bien." Quizás, entonces, desde esas premisas me pregunto: ¿Cómo pensar y reordenar las gramáticas sexopolíticas contemporáneas desde lo contemporáneo? ¿Cómo no lamentarnos por el presente y, en cambio, ver su potencia? ¿Se puede contar una historia, la historia de las sexualidades y sus activismos, de modo diferente desde Latinoamerica? Acaso, efectivamente, la disidencia sexo-genérica quedó perdida o prendida en el pasado (y por pasado me refiero a los setentas, ese momento atravesado por la violencia pero también por apasionadas imaginaciones libertarias)?

Éxito, acorde con el diccionario, quiere decir final tanto como resultado feliz. Este pequeño movimiento de matices -en el que pueden caber un sin fin de posibilidades- habilita también alternativas para la reflexión. En primer lugar, nos da pie para zanjar una cuestión: no todo tiempo pasado fue mejor. Sólo lo aparenta por su misma condición. Pequeño éxito paradojal del tiempo y primera propuesta: en el texto de Epps, la carga afectiva convierte el pasado en una suerte de memoria utópica. Pero no sólo al pasado. Las teorías y activismos sobre las sexualidades disidentes están inmersos en relaciones de poder, tramados en relaciones (transnacionales) que afectan el ver, el saber, el sentir, el desear e incluso el poder en tanto habilidad. Innegablemente, también, algo como un exotismo fija la mirada de un sector de la academia norteamericana en nuestro pasado latinoamericano y marica. Es el deseo por ese cuerpo joven -sexual y textual, literario y social- que ya no es: por el cuero sudado y moreno del miché brasilero, por el puño en alto del revolucionario sudaca, por la travesti con collares y aretes en plena dictadura. Por esa Latinoamérica pobre y salvaje, feliz incluso en la enfermedad, insurrecta incluso cuando abatida, siempre híbrida, siempre mística. La añoranza por ese tiempo hermoso de políticas, cuerpos y textos deseantes ahora, aparentemente, perdidos en la institucionalización, en el neoliberalismo e, incluso, en lo queer.

Mientras escribo esto tengo dos pestañas del explorador abiertas. En la primera está el nuevo "Protocolo General de Actuación de Registros Personales y Detención para Personas Pertenecientes al Colectivo L.G.B.T." escrito por una mujer trans y publicado por el Ministerio de Seguridad a pocos días de la marcha del orgullo. En la otra, puedo leer el comunicado que emitió rápidamente la FALGBT en el que si bien se manifiesta en contra de algunos de los puntos, reclama no haber participado en la redacción. Reformulado: reclama un diálogo directo con el sistema represor y penitenciario.
* Dra en Letras (UBA), Investigadora del IIEGE,UBA/CONICET. Profesora en la UBA, UNA y UNTREF y colaboradora del Suplemento "Soy" de Página 12. Publicó : Ficciones lesbianas. Literatura y afectos en la literatura argentina (ed madreselva, 2016). 
Por un segundo, me siento tentada de darle la razón a Brad. Y, sin embargo, creo que cómo se cuenta la historia y dónde se pone el ojo (y, el Estado, la bala) importa.

Hoy, a pesar y contra el neoliberalismo, en un momento en el que se está agravando la precariedad social y económica, la fuerza de la disidencia vuelve a presentarse -organizada- en cuerpos de tramas populares, en cuerpos que, con y a pesar de sus posibles contradicciones, acarrean intemperies y cuestionan el orden de lo político. Sin lugar a dudas, se están inaugurando nuevas formas del feminismo. Hay nuevas comunidades proponiendo vínculos que no sólo se enfrentan a la familia -en diversos sentidos- sino que provocan roces y desvíos temporales, conexiones afectivas inesperadas. Hay críticas radicales de los cuerpos y cuerpos que resisten radicalmente.

Ni hoy ni nunca la sexualidad por sí sola fue un salvavidas. Los problemas y también los alivios residieron siempre en las asociaciones y en las alianzas, en los contactos que moldeana los cuerpos, sus formas de sociabilidad y sus recorridos. Así como en la Inglaterra de ayer se unieron bajo una misma e inesperada bandera gays, lesbianas y mineros, así como Epps piensa hoy en la potencia de lo crip y homenajea con nostalgia rebelde a Perlongher y Lemebel, yo me pregunto: ¿qué otras comunidades existen hoy, acá, en esta Buenos Aires que, en tanto centro, está siempre un tanto ladeada y un poco vencida?

En nuestro mundo todavía moderno, el nombre propio tiende a borrar a la multitud, lo sabemos. Pero intuyo que en nuestro escenario es posible volver a hablar de redes, de flujos, de fuerzas, de políticas colectivas. Como tal vez diría Sara Ahmed, hay algo de una obstinación creativa amontonando a todxs aquellxs que luchan por modificar los territorios de la existencia: a aquellxs que ponen el cuerpo, que bloquean las corrientes del sentido común y que se arriesgan, en el mismo gesto, a la violencia de un Estado que teme y, por eso, se defiende o, mejor dicho, ataca. Estoy pensando, por ejemplo, en la disidencia misoprostolera o en las travas abolicionistas: la rabia de la primera haciendo eco y familia en la furia de las segundas; pienso en la carne indisciplinada del activismo gordx o en la irritación llevada al punto de explosión de todas esas mujeres -de edades variadas, de colores y cuerpos disímiles, de clases dispares- aunadas en un grito y en muchas marchas: Ni una menos.

Estas experiencias de disenso o disidencia no sólo producen momentos de subjetivación colectiva sino que, además, tienden a manifestarse como experiencias estéticas: crean formas de decir, de nombrar o de representar tanto para aquello que pide paso como para aquello que sucedió; y, al hacerlo, alteran las gramáticas sociales y sus discursos: proponen travesías que horadan los traumas sociales constitutivos del hetero-capitalismo, al tiempo que se reapropian y resignifican muchas de esas pulsiones vitales que, como nota Epps, el propio sistema nos pretende expropiar. Así, por ejemplo, frente al slogan conservador que, importado de España, se usó en la campaña por el matrimonio igualitario (2010): "El mismo amor, los mismos derechos", algunos carteles del 8 de marzo (2017) leían: "Amar te mata".

Como se hizo explícito con las detenciones arbitrarias de lesbianas y bisexuales el 8 de marzo de 2017, con la quema de la cara de Butler/bruja en Brasil o, de modo más extremo, con los lamentablemente cotidianos travesticidios, según algunxs nuestros movimientos encarnan imaginarios de desastre. Sin embargo, para nosotrxs, son encuentro y celebración -aunque no necesariamente felicidad-; delinean o encarnan fugas hacia horizontes que por lejanos o por nublados no son menos presentes. En esos recorridos la trama de ficciones y de imaginaciones se complejiza; en esos recorridos se altera, en palabras de Rancière, la distribución de lo sensible: lxs que no contaban empiezan a hacerlo (en los dos sentidos de la palabra) y entonces se hacen escuchar relatos que son también acción. De ahí la potencia. De ahí la pasión. 
"Estamos en guerra" escribió sobre su pecho una chica durante el último paro de mujeres (2017): sólo sus tetas y sus ojos al aire. A su alrededor: "la puta que te paró", "la sororidad mató al macho", "abortar es dar vida", "las lesbianas no paramos de garchar". Sin lugar a dudas, la superficie de los cuerpos individuales y colectivos se afectan mutuamente en los contactos que propician y la potencia de acción se incrementa. Tal vez la revolución quedó en el pasado, pero no la revuelta: ese desorden, punto en el que la dirección cambia de forma pronunciada. El pasado no se perdió: nos dio cuerpo, nos hizo encontrar y multiplicarnos.

Así como Perlongher se dijo "Loca" -marica popular, intrépida y escandalosa-y le pidió al Estado que entregue su culo cuando ser queer era ser macho y rubio, Lohana Berkins insistió en su ser "Mujer" e "India" a pesar de o con su cuerpo: "en un mundo de gusanos capitalistas hay que tener mucho coraje para ser una mariposa", repetía con su voz grave y amable. Pero, además, cuando el "orgullo" y la "diversidad" estaban ganando la partida, cuando el "trabajo sexual" quiso hacer ley de un destino no elegido, al grito de "abolicionista" se tapó el escote de voluptuosa silicona, tomo la calle y junto a su prole-familia elegida, creada- les organizó a ambos la contramarcha. ${ }^{1}$

Así como el activismo queer -sobre todo el europeo- hizo del culo gozosa bandera, hoy, a lo largo de toda la Argentina, lesbianas y bisexuales, en un continuum feminista, hacen carne de otra política anti-maternalizante y cuestionan la potestad médica: se niegan al disciplinamiento de los cuerpos en manos del Estado, del derecho, de la medicina, de la Iglesia. Parten de tres ad-hoc: el cuerpo es propio, el saber y la experiencia son siempre situados y los circuitos fármaco-políticos (siempre económicos e ideológicos) tienen que ser desviados. Si la legalización del aborto es un abismo, ellas lo saltan: propician agenciamientos y circulan información. Así, en un continuo de flujos y sangre, actúan. Celebrantes, desafían y corrompen el imperativo histórico que da forma y sentido a todo cuerpo con capacidad gestante.

Frente a la Ley, la pasión y la comunidad siguen siendo la respuesta. Porque es, justamente, en los encuentros y en las alianzas que se crea un estado de excepción: catástrofe para el Estado que se enfrenta a la suspensión de su poder. Después, la ley impersonal e ideológica y el mercado acaparador y oportunista procurarán apropiarse de todo, asimilar el riesgo y convertirlo en norma e, incluso, en valor. Pero eso es después. Hoy, nuestros cuerpos, nuestros saberes y nuestras acciones son peligrosas, síntomas de patologías a las que el positivismo de principios del siglo XX temía tanto como los conservadurismos de hoy.
1. Este párrafo pertenece al artículo "Poses queer/feministas" (Arnés, Laura y Domínguez, Nora), leído en el Workshop: "Los viajes de la teoría: entre la teoría queer y el feminismo", 6 y 7 de octubre 2016, organizado po IIEGE en el Centro Franco Argentino. 
